\title{
Assessing the impacts of the first year of rotavirus vaccination in the United Kingdom
}

R Marlow ${ }^{1}$, P Muir ${ }^{2}$, B Vipond ${ }^{2}$, M Lyttle ${ }^{1}$, C Trotter ${ }^{3}$, A Finn 4

1. Bristol Royal Hospital for Children, University Hospitals Bristol NHS Foundation Trust, Bristol, UK

2. Public Health England, South West, Bristol, UK

3. Disease Dynamics Unit, Department of Veterinary Medicine, University of Cambridge, UK

4. Schools of Clinical Sciences \& Cellular \& Molecular Medicine, University of Bristol, UK

Correspondence: Robin Marlow (robin.marlow@bristol.ac.uk)

Citation style for this article:

Marlow R, Muir P, Vipond B, Lyttle M, Trotter C, Finn A. Assessing the impacts of the first year of rotavirus vaccination in the United Kingdom. Euro Surveill. 2015;20(48): pii=30077. DOI: http://dx.doi.org/10.2807/1560-7917.ES.2015.20.48.30077

Article submitted on 25 November 2014 / accepted on 27 April 2015 / published on 03 December 2015

The United Kingdom (UK) added rotavirus (RV) vaccine (Rotarix GlaxoSmithKline) to the national vaccine schedule in July 2013. During the 2012-2014 rotavirus seasons, children presenting to the Bristol Royal Hospital for Children Emergency Department with gastroenteritis symptoms had stool virology analysis (real-time PCR) and clinical outcome recorded. Nosocomial cases were identified as patients with non-gastroenteritis diagnosis testing positive for rotavirus > 48h after admission. In comparison to average pre-vaccine seasons, in the first year after vaccine introduction there were $48 \%$ fewer attendances diagnosed with gastroenteritis, $53 \%$ reduction in gastroenteritis admissions and a total saving of 330 bed-days occupancy. There was an overall reduction in number of rotavirus-positive stool samples with $94 \%$ reduction in children aged under one year and a $65 \%$ reduction in those too old to have been vaccinated. In the first year after the introduction of universal vaccination against rotavirus we observed a profound reduction in gastroenteritis presentations and admissions with a substantial possible herd effect seen in older children. Extrapolating these findings to the UK population we estimate secondary healthcare savings in the first year of ca $£_{7.5}\left(€_{10.5}\right)$ million. Ongoing surveillance will be required to determine the long-term impact of the RV immunisation programme.

\section{Introduction}

Acute gastroenteritis is one of the commonest paediatric presenting complaints with the predominant cause being rotavirus ( $R V$ ). Almost all children will have suffered from RV gastroenteritis by the time they are five years old. Worldwide, RV is estimated to be responsible for more than 450,000 deaths in children every year [1] although with good nutritional status and access to medical care, death due to RV infection is exceptionally rare. In Bristol, as in the whole of the United Kingdom
(UK), it is a highly seasonal infection occurring in annual epidemics in the late winter and early spring, although in tropical regions it persists year-round [2]. $\mathrm{RV}$ is a highly infectious organism, able to spread even in countries with high standards of hygiene. The only effective control strategy is vaccination [3]. The World Health Organization has recommended that all countries should include a vaccine against RV in their childhood schedules [4]. As of March 2015, only 12 of the 75 countries to have introduced RV vaccination into their primary infant schedules were in Europe [5].

A 2007 health economic analysis estimated that if the vaccine could be purchased for a favourable price, RV vaccination could be cost-effective in the UK $[6,7]$. Although the UK has been at the forefront of universal childhood programmes using meningococcus group $C$ conjugate and more recently live attenuated influenza vaccines, vaccination against a disease that is extremely common but rarely leads to death or longterm morbidity required a different paradigm and it was not until July 2013 that RV immunisation was introduced into the routine childhood vaccine schedule at two and three months of age [8]. With an upper age limit of 24 weeks placed on the last dose of vaccine due to the reported association with intussusception, a catch-up campaign was not possible. It is now important to evaluate the impact of this measure on the burden of children's illness and to evaluate whether the f20 (€28) million annual healthcare saving predicted by the Department of Health will be realised [9].

\section{Methods}

Bristol Royal Hospital for Children is the only hospital admitting children in Bristol and serves a population of ca 55,000 children under the age of five years. Regardless of referral source, all patients are first seen in the paediatric emergency department. Since late February 2012 we have carried out routine surveillance 


\section{FIGURE 1}

Distribution of all-cause gastroenteritis attendances, fortnightly totals, Bristol Royal Hospital for Children, United Kingdom, 2012-2014

A. $2012(n=1,464)$

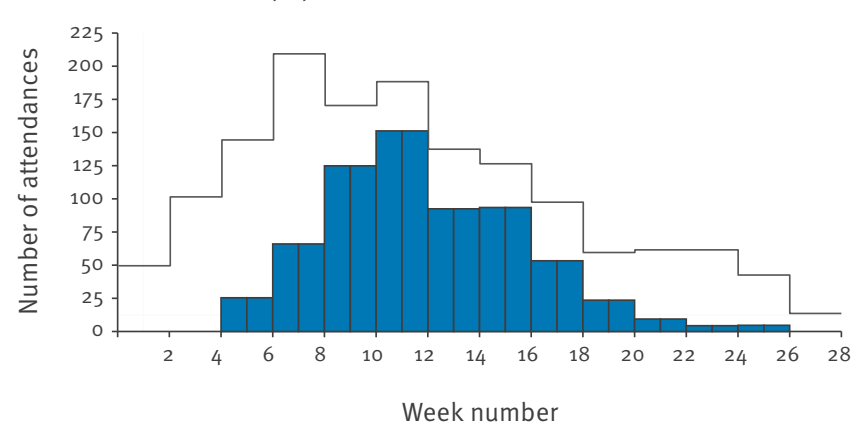

B. $2013(n=1,239)$

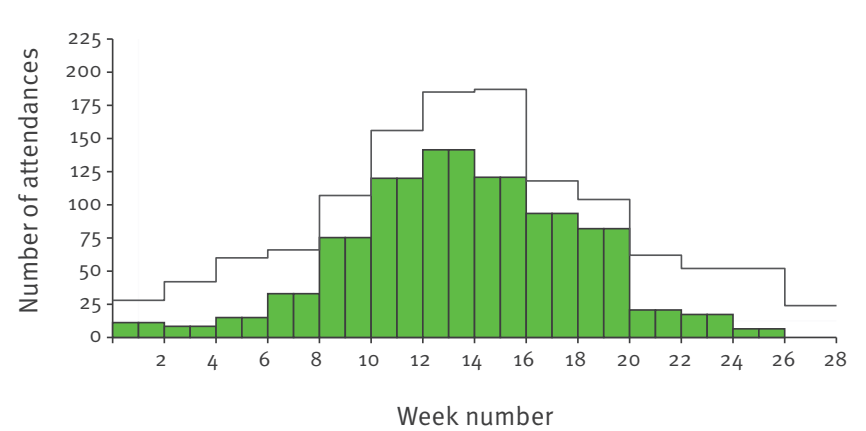

C. $2014(n=706)$

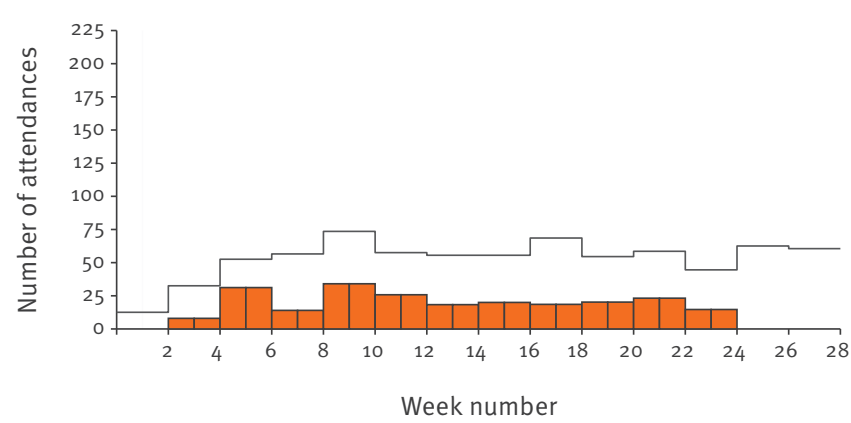

Shaded area represents proportion estimated to be caused by rotavirus.

of attendances with symptoms of gastroenteritis during successive RV seasons (weeks 1-27). All children $<18$ years presenting to the emergency department with symptoms of gastroenteritis ( $>2$ loose stools and/or $>1$ episode of forceful vomiting in the last 24 hours) had a standardised assessment (Vesikari score) [10] and had routine screening for viral gastroenteritis pathogens. Samples were tested for rotavirus and a panel of other gastroenteritis viruses using multiplex PCR. Patients' clinical diagnosis was identified though note review and use of clinical coding. As enhanced surveillance started in late February 2012, data for weeks 1-7 of the 2012 epidemic were retrospectively obtained from a database of hospital records with coded diagnoses. Inpatient bed occupancy was calculated in hours from

\section{FIGURE 2}

Distribution of all-cause gastroenteritis admissions, fortnightly totals, Bristol Royal Hospital for Children, United Kingdom, 2012-2014

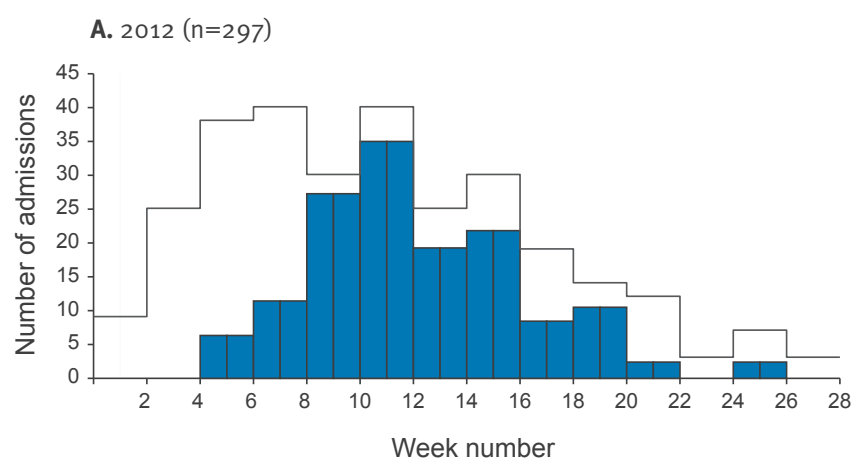

B. $2013(n=288)$

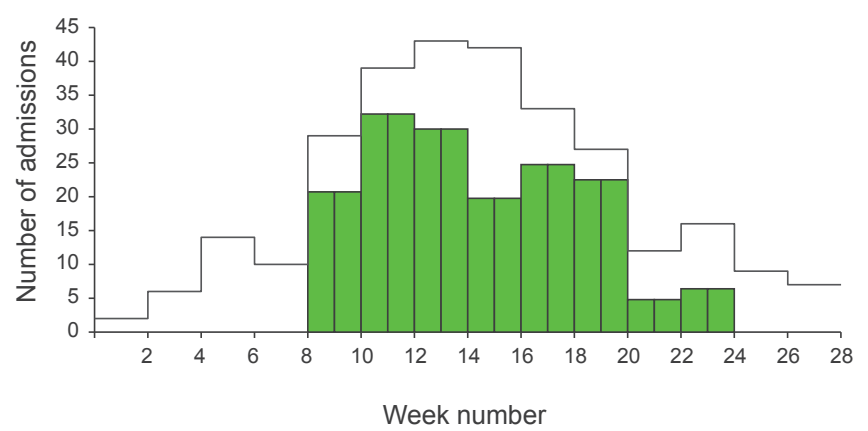

C. $2014(n=137)$

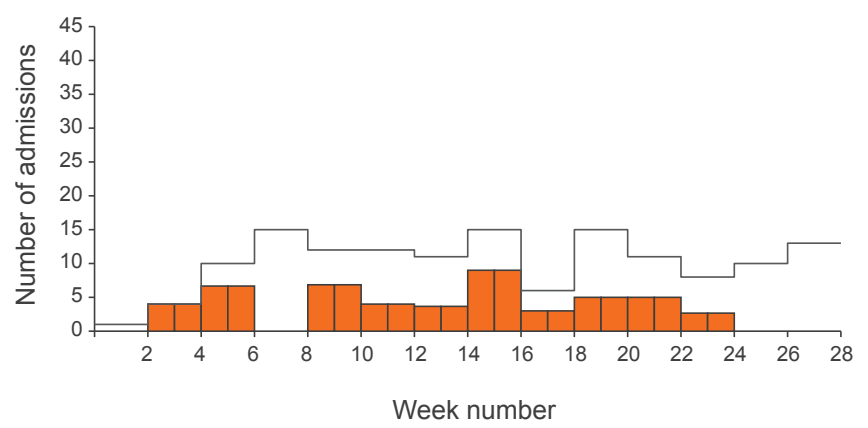

Shaded area represents proportion estimated to be caused by rotavirus.

time of admission to time of hospital discharge. As not all patients were able to provide a stool sample, the proportion of all gastroenteritis attendances and admissions that were caused by rotavirus was estimated from the proportion of samples received over the same time period that were confirmed to be rotavirus positive. Similarly, the proportion of positive results from stool samples received from children of different ages was used to estimate the overall age distribution of rotavirus cases.

Our strict hospital infection control policy meant that any patient who developed gastroenteritis while admitted was tested for viral causes. By linking all positive stool results from our laboratory to admission date 
and diagnosis, any later samples from admitted gastroenteritis patients could be included and patients admitted with a non-gastroenteritis diagnosis who tested positive for RV more than 48 hours after their admission could be retrospectively identified as nosocomial infection. By definition these patients were not included in the analysis of the attendance or admitted cohorts.

In the UK, hospitals are paid according to an annually negotiated tariff based on the coded discharge diagnoses for an episode of care. From the 2013/2014 National Health Service tariffs [11] the cost of an emergency department attendance (VBogZ) was $£_{96}\left(€_{135}\right)$, and short-term viral gastroenteritis admission (PA21B) was $\AA_{504}\left(€_{707}\right)$. We used these to estimate the costs saved by the health service through RV vaccination.

Data were recorded in Microsoft Access. Data cleaning and statistical analysis was done using $R$ [12]. Significance of annual changes in rates of attendance and admission were assessed using negative binomial regression model using year as a cofactor. MannWhitney $\mathrm{U}$ test was used to compare age distributions and chi-squared test for proportions.

As this project involved analysis of the results of non-invasive standard clinical investigation and anonymised routine clinical data, this work was assessed as being a service evaluation by University Hospitals Bristol NHS Foundation Trust, with no ethical review or informed consent for research required.

\section{Results}

\section{All cause gastroenteritis}

In total, during the three rotavirus seasons there were 3,410 emergency department attendances with median age 18 months (interquartile range (IQR): 9-42; range: 0-202) and 722 admissions with median age 17 months (IQR: 9-43; range: 0-202). Between 2012 and 2013 there was significant variation in the number of all-cause gastroenteritis attendances $(p<0.001)$ but not in the proportion admitted $(p=0.7)$. In 2014 there was a $48 \%$ reduction in attendances $(p<0.001)$ and a $53 \%$ reduction in admissions $(p<0.001)$ compared with the mean in the pre-vaccine years 2012 and 2013. There was a $67-71 \%(p<0.001)$ reduction in the total number of bed days occupied: equating to 1.7-2 fewer occupied beds in the hospital every day during the six-month period examined (Table 1). Median age of attendance rose significantly in the winter following vaccine introduction (Table 2$)(p<0.05)$. There was no significant difference in length of admission.

Figure 1 compares the fortnightly total numbers of attendances to the emergency department with gastroenteritis symptoms, demonstrating the onset of the gastroenteritis season for the three years of the study. Pre-vaccine rates of gastroenteritis attendance peaked in week 7 of 2012 and week 15 of 2013, while in 2014

\section{FIGURE 3}

Age distribution of all-cause gastroenteritis attendances $<18$ years of age, Bristol Royal Hospital for Children,

United Kingdom, 2012-2014

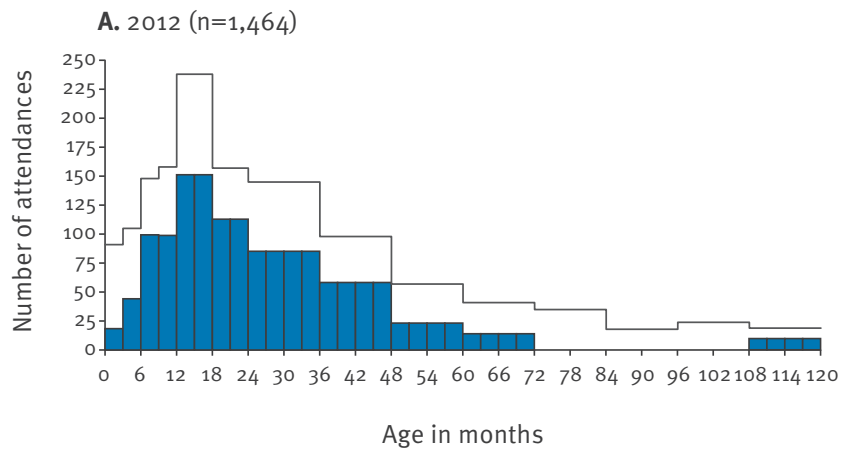

B. $2013(n=1,239)$

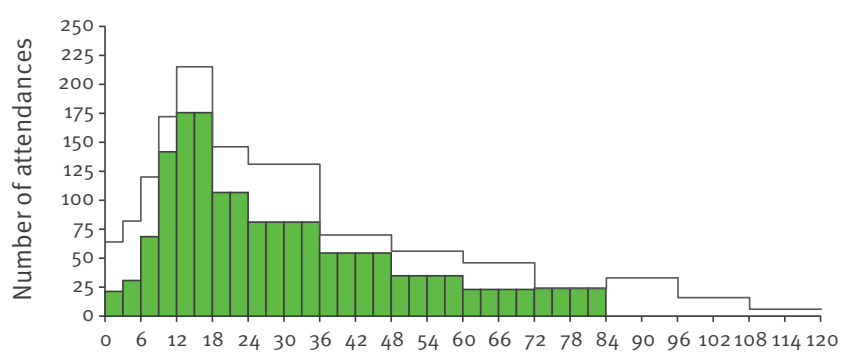

Age in months

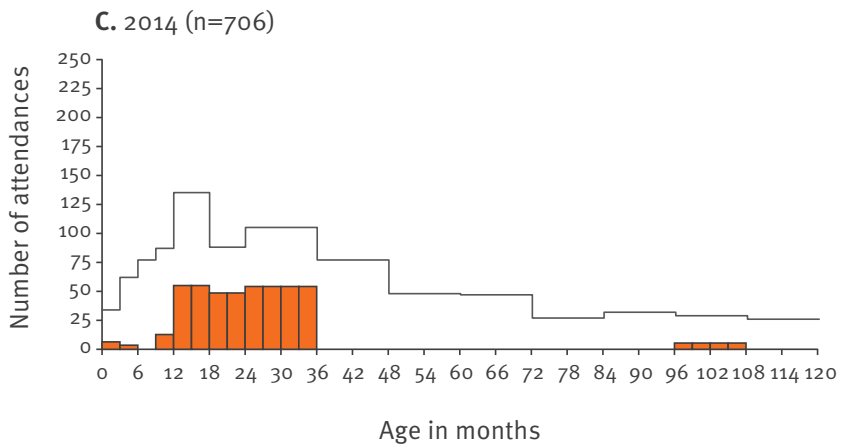

Only ages 0-120 months shown for scale. Shaded area represents proportion estimated to be caused by rotavirus.

the seasonal epidemic was attenuated with a possible peak between weeks 8 to 10 . Figure 2 demonstrates the corresponding number of patients admitted with gastroenteritis per fortnight during the study.

The age distributions of cases for the three years show that after vaccine introduction there were reductions in number of attendances (Figure 3) and admissions (Figure 4) across all age groups and not just in the infants under the age of one that would have been eligible for the vaccine.

\section{Rotavirus gastroenteritis}

During the surveillance period samples were obtained from $35 \%, 30 \%$ and $30 \%$ of gastroenteritis attendances with diarrhoea in the three respective seasons. In 2012 and $2013,54 \%$ and $65 \%$ of these were positive for RV; 
TABLE 1

Number of cases of all-cause gastroenteritis aged $<18$ years seen, Bristol Royal Hospital for Children, United Kingdom, January-July 2012-2014 ( $\mathrm{n}=3,409)$

\begin{tabular}{|c|c|c|c|c|c|c|}
\hline & & $2012^{a}$ & 2013 & 2014 & $\begin{array}{c}\text { Change } \\
2012 \text { to } 2014\end{array}$ & $\begin{array}{c}\text { Change } \\
2013 \text { to } 2014)\end{array}$ \\
\hline \multirow{3}{*}{ All-cause gastroenteritis } & Attendances & 1,464 & 1,239 & 706 & $-52 \%(p<0.001)$ & $-43 \%(p<0.001)$ \\
\hline & Admissions & 297 & 288 & 137 & $-54 \%(p<0.001)$ & $-52 \%(p<0.001)$ \\
\hline & Bed days occupied & 506 & 450 & 148 & $-71 \%(p<0.001)$ & $-67 \%(p<0.001)$ \\
\hline
\end{tabular}

a In 2012, 511 attendances and 114 admissions were identified through retrospective coding.

\section{TABLE 2}

Comparing age at attendance or admission and length of admission for all-cause gastroenteritis $<18$ years, Bristol Royal Hospital for Children, United Kingdom, 2012-2014 ( $\mathrm{n}=3,409)$

\begin{tabular}{|c|c|c|c|c|}
\hline \multicolumn{2}{|c|}{ All-cause gastroenteritis } & 2012 & 2013 & 2014 \\
\hline \multirow{2}{*}{ Median age of } & Attendance & $\begin{array}{c}17 \text { months (IQR: } 9-41) \\
(p<0.001)\end{array}$ & $\begin{array}{c}17 \text { months (IQR: } 9-36) \\
(p<0.001)\end{array}$ & 23 months (IQR: 11-57) \\
\hline & Admission & $\begin{array}{c}18 \text { months (IQR: } 9-59) \\
(p=0.79)\end{array}$ & $\begin{array}{c}15 \text { months (IQR: } 9-32) \\
(p=0.008)\end{array}$ & 20 months (IQR: 9-46) \\
\hline \multicolumn{2}{|l|}{ Length of admission } & $\begin{array}{l}16 \text { hours (IQR: } 6-39) \\
(p=0.34)\end{array}$ & $\begin{array}{l}16 \text { hours (IQR: 6-30) } \\
(p=0.29)\end{array}$ & 14 hours (IQR: 6-25) \\
\hline
\end{tabular}

IQR: interquartile range.

$\mathrm{p}$ values describe significance of differences in comparison to 2014 .

\section{TABLE 3}

Number of rotavirus positive samples and percentage testing positive by month in children $<$ age of 18 years, Bristol Royal Hospital for Children, 2012-2014 (n=677)

\begin{tabular}{|c|c|c|c|c|c|c|c|c|c|c|}
\hline & Jan & Feb & Mar & Apr & May & Jun & $\begin{array}{c}\text { Total number } \\
\text { of positive } \\
\text { samples }\end{array}$ & $\begin{array}{l}\text { Number of } \\
\text { positive }<1 \\
\text { year old }\end{array}$ & $\begin{array}{c}\text { Number of } \\
\text { positive }>1-4 \\
\text { years old }\end{array}$ & $\begin{array}{c}\text { Total } \\
\text { number of } \\
\text { samples }\end{array}$ \\
\hline 2012 & $1(8 \%)$ & $29(57 \%)$ & $78(76 \%)$ & $35(66 \%)$ & $6(25 \%)$ & $2(8 \%)$ & $151(54 \%)$ & $72(48 \%)$ & $77(51 \%)$ & 279 \\
\hline 2013 & $4(31 \%)$ & $19(56 \%)$ & $86(77 \%)$ & 52 (69\%) & $19(56 \%)$ & $5(26 \%)$ & $185(64 \%)$ & $88(48 \%)$ & $92(47 \%)$ & 286 \\
\hline 2014 & $4(44 \%)$ & $8(35 \%)$ & $13(43 \%)$ & $5(25 \%)$ & 6 (33\%) & $4(33 \%)$ & $40(35 \%)$ & $4(10 \%)$ & 35 (88\%) & 112 \\
\hline
\end{tabular}

in 2014 this proportion fell to $36 \%$ ( $p<0.001$ ) (Table 3). Combining the age distributions of positive samples and the overall gastroenteritis attendance rates (Figure 1) reveals that as well as a $94 \%$ drop in RV attendances among those less than 12 months of age, there was also a $67-70 \%$ reduction in those too old to have been vaccinated ( $1-4$ years).

In children who were admitted with gastroenteritis, the proportions of RV positive samples per year were $59 \%$, $63 \%$ and $40 \%$, respectively. The number of gastroenteritis admissions likely to be attributable to RV fell from 175 in 2012 and 180 in 2013 to 55 in 2014: a 69\% reduction $(p<0.001)$.

We identified six cases of nosocomial RV transmission in 2014 compared with eight in 2012 and 15 in 2013 (p $=0.16)$.

\section{Financial effects}

Between the years 2012 and 2013 we calculated RV to be responsible for a mean of 14.5 ED attendances and 3.3 admissions per 1,000 children under the age of five. In 2014 this fell to 4.6 attendances and 1 admission per 1,000 children under five years of age. If this fall is due to $R V$ vaccine use, extrapolating these findings to the national paediatric population under the age of five years [13] would equate to approximate first year reductions of 35,700 ED attendances and 8,120 admissions. Before one whole birth cohort had been protected, we calculate secondary care savings of ca $£_{7.5}\left(€_{10.5)}\right.$ million in the first year of implementation.

\section{Discussion}

This is the first report of RV vaccine impact in the UK. This early evidence points to direct as well as possible indirect effects of this new immunisation programme 


\section{FIGURE 4}

Age distribution of all-cause gastroenteritis admissions < 18 years of age, Bristol Royal Hospital for Children, United Kingdom, 2012-2014

A. $2012(n=297)$

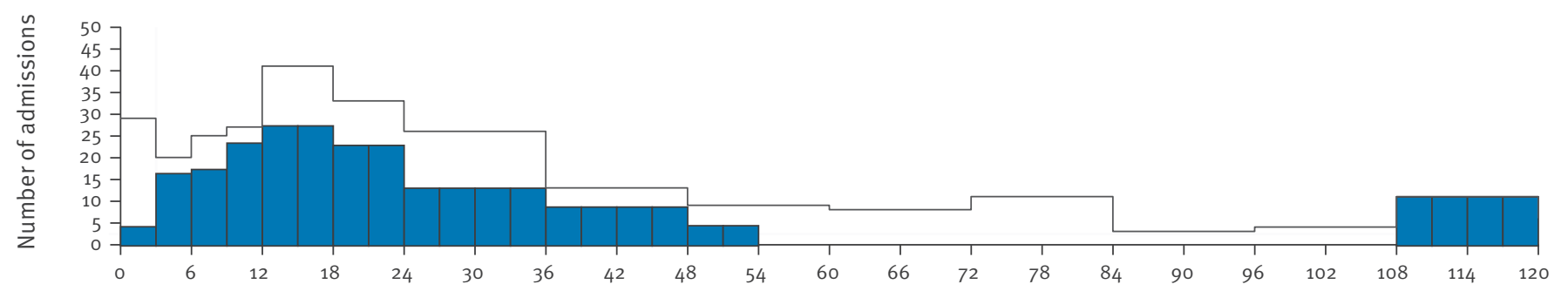

Age in months

B. $2013(\mathrm{n}=288)$

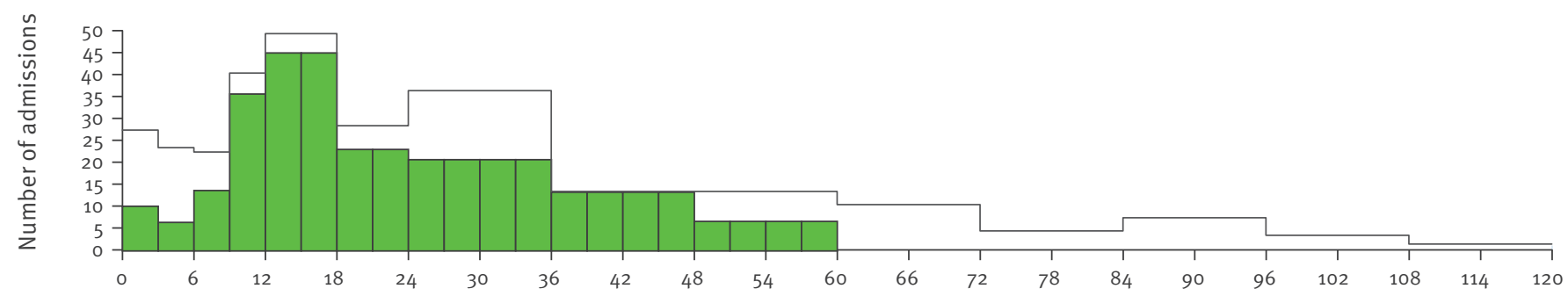

Age in months

C. $2014(\mathrm{n}=137)$

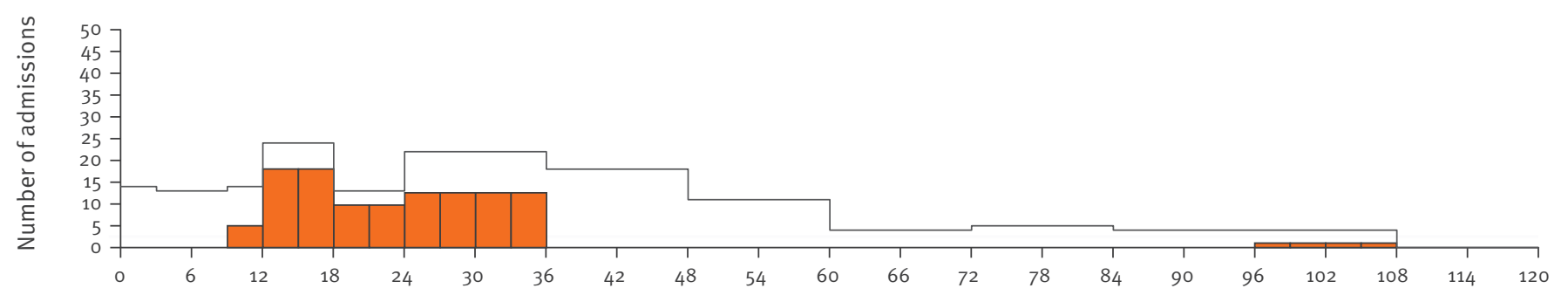

Age in months

Only ages 0-120 months shown for scale. Shaded area represents proportion estimated to be caused by rotavirus.

and suggests that optimistic predictions of significant impacts upon hospital emergency department and inpatient workloads during the peak winter period may have been well founded.

It is important to have clear baseline data against which to assess the impact of any intervention. Although we have only two years of data before vaccine introduction, our single site study has the advantage of consistent sample collection methods with no change in testing behaviour throughout. In a vaccine probe study of this kind [14], using acute gastroenteritis attendances may be less specific but is more sensitive than restricting analysis to laboratory-confirmed cases and is more clinically relevant.
National UK emergency department standards mean that patients must either be admitted or discharged within four hours to avoid financial penalty. This means that our patients had to have a sufficiently high stool frequency to produce a sample within this timeframe. Many of those requiring admission for rehydration were unable to produce a sample in hospital. Our sampling percentage is consistent with other similar surveillance studies [15-17]. The vaccine used in the UK (Rotarix) is a live attenuated form of one of the most commonly circulating human RV strains (G1P8). Although the PCR test used in this study could not distinguish wild-type virus from the vaccine strain, there were only three positive samples from children old enough to have been eligible for the vaccine. A limitation of our study is that since the project start date was after the beginning of 
the first seasonal epidemic, the first seven weeks of data were collected retrospectively.

As can be seen from the differences between 2012 and 2013, RV epidemics vary in size between years even in the absence of immunisation. It has recently been reported that 2014 was an exceptionally low RV year in both France and the Netherlands [18], despite neither country routinely using a RV vaccine. Although it is possible that the UK's 2014 epidemic was also unusually small coincidentally to the commencement of vaccination, we feel it is unlikely that the entire effect observed effect is due to this. Case-control studies have shown that both licensed RV vaccines provide excellent direct protection in industrialised countries $[19,20]$ with evidence of herd protection [21]. Mathematical models predict that after the introduction of RV vaccine there will be an increased average age of cases and a delay in the seasonal peak [22] [23]. With widespread vaccination removing the majority of susceptible patients, a 'honeymoon period' of very low disease incidence shortly after the introduction is also expected. But with the gradual accumulation of an unvaccinated naive fraction, at some point there may be a rebound rise in cases. Key variables that determine the timing of this phenomenon include vaccine uptake and consistency in coverage over time and place, duration of vaccine-induced protection, and the transmissibility of the infection. The reduced number of cases seen in children too old to have been vaccinated is unexpected; it is not possible to discern whether this is evidence of herd effect or represents the true size of the underlying 2014 UK seasonal epidemic. For reasons unknown, rotavirus epidemiology appears to have changed abruptly in the Netherlands, but in the absence of clinical disease (or vaccination), susceptible patients will continue to accumulate creating a population susceptible to future outbreaks. To date this has not been reported in 2015 [24].

The United States (US) introduced a pentavalent RV vaccine (RotaTeq- SMSD) in 2006 and, with 50-60\% vaccine coverage, a dramatic reduction in cases was observed the following season [25]. After a resurgence of disease in year two, cases have subsequently oscillated in number biennially, cycling between $60 \%$ and $80 \%$ lower than the pre-vaccine baseline [26]. These dynamics may be due to the suboptimal vaccine uptake, which in 2013 was still only $72.6 \%$, 10\% lower than other primary vaccines [27]. In 2006, Belgium was the first European country to introduce the same vaccine as the UK (Rotarix) and rapidly achieved vaccination coverage > 90\% [19]. To date only three years' post-introduction data have been published, with no rebound yet reported [28]. Public Health England have reported UK RV vaccine coverage rates of $93 \%$ first dose and $88 \%$ complete course and a $67 \%$ reduction in RV laboratory reports compared with a ten year average [29]. Our local RV vaccination rates were similar, $91 \%$ first dose and $86 \%$ completed course. With a different vaccine at higher coverage rates than the US, the
UK's eventual epidemiology is likely to be more similar to Belgium. Ongoing surveillance will be important not only to track any rebound but also because the monovalent vaccine (Rotarix) has relatively lower efficacy against non $\mathrm{G}_{1}$ strains of virus $[30,31]$ and may result in their relative emergence as overall $\mathrm{RV}$ circulation declines. However natural year-to-year genotype fluctuations make interpretation of such ecology challenging. After Brazil introduced the monovalent vaccine, a three year progressive rise in $\mathrm{G}_{2} \mathrm{P}_{4}(89,93,100 \%)$ was followed by a sudden return of $\mathrm{G}_{1} \mathrm{P} 8$ (68\%) in 2009 , with non-vaccine genotypes predominating subsequently on a background of sustained public health benefits with significant reductions in gastroenteritis attendances, admissions and deaths [32].

The UK health economic analysis [33] estimated that $\mathrm{RV}$ was responsible for 9.3 emergency department consultations and 4.5 admissions per 1,000 children under the age of five years and predicted secondary care savings of $f_{7.4}\left(€_{10.4)}\right.$ million with the use of RV vaccine, almost exactly the same as our findings. The impact on primary care is not yet known, but any reduction in the estimated 100,000-150,000 annual consultations due to RV [33] will have had wider benefits by allowing others to access pressured services. However, while the prevention of healthcare utilisation is important, the additional benefits of this vaccine to society at large may have been much greater by sparing children an unpleasant disease, sparing families time missed from productive work while caring for them and by preventing associated secondary cases.

Just one season after vaccine introduction, it is too early to conclude that our data entirely reflect vaccine effectiveness rather than epidemiological happenstance. But they provide a first description of remarkable trends which will need to be followed closely over the seasons to come.

\section{Acknowledgements}

Thank you to all the doctors and nurses in Bristol Royal Hospital for Children's Paediatric Emergency Department who helped with data and sample collection, Barrie Bishop who assisted with extracting coding data, and our research nurses Sarah Potter and Hannah Spires. The study was funded in part by an investigator-led grant from GlaxoSmithKline Biologicals. GlaxoSmithKline had no role in study design, data collection, data analysis, data interpretation, nor in the writing of the report. The study was supported by the National Institute for Health Research's Health Protection Research Unit in Evaluation of Interventions. The views expressed are those of the author(s) and not necessarily those of the National Health Service, the National Institute for Health Research, the Department of Health or Public Health England.

\section{Conflict of interest}

RM: travel bursaries from GlaxoSmithKline; AF: consultancy and clinical research for all the main vaccine companies including GSK and Sanofi Pasteur MSD (all income is paid to his employers); PM, BV, ML and CT have no conflict of interest. 


\section{Authors' contributions}

Robin Marlow: protocol design, wrote manuscript and statistical analysis; Peter Muir - sample analysis, manuscript comments; Barry Vipond: assay development and sample analysis; Mark Lyttle: study design, study management, data collection; Caroline Trotter: assisted with writing manuscript and statistical analysis; Adam Finn: protocol design, assisted with writing manuscript.

\section{References}

1. WHO-coordinated Global Rotavirus Surveillance Network,Tate JE, Burton AH, Boschi-Pinto C, Steele AD, Duque J, Parashar UD. 2008 estimate of worldwide rotavirus-associated mortality in children younger than 5 years before the introduction of universal rotavirus vaccination programmes: a systematic review and meta-analysis.Lancet Infect Dis. 2012;12(2):136-41. .DOI: 10.1016/S1473-3099(11)70253-5 PMID: 22030330

2. Atchison CJ, Tam CC, Hajat S, van Pelt W, Cowden JM, Lopman BA. Temperature-dependent transmission of rotavirus in Great Britain and The Netherlands. Proc R Soc B Biol Sci. 2010 Mar 22;277(1683):933-42.

3. Marlow RD, Finn A. The promise of immunisation against rotavirus.Arch Dis Child. 2012;97(8):736-40. .DOI: 10.1136/ archdischild-2011-301472 PMID: 22611059

4. World Health Organization (WHO). Weekly Epidemiological Record (WER). 18 December 2009, vol. 84, 50 (pp 533-540). Geneva: WHO; 2009. [Accessed 25 Oct 2010]. Available from: http://www.who.int/wer/2009/wer8451_52/en/index.html

5. World Health Organization (WHO). WHO immunization schedule information. Geneva: WHO. [Accessed 15 Sep 2014]. Available from: http://apps.who.int/immunization_monitoring/ globalsummary/schedules

6. Jit M, Edmunds WJ. Evaluating rotavirus vaccination in England and Wales. Part II. The potential cost-effectiveness of vaccination.Vaccine. 2007;25(20):3971-9. .DOI: 10.1016/j. vaccine.2007.02.070 PMID: 17400341

7. Lorgelly PK, Joshi D, Iturriza Gómara M, Gray J, Mugford $M$. Exploring the cost effectiveness of an immunization programme for rotavirus gastroenteritis in the United Kingdom.Epidemiol Infect. 2008;136(1):44-55 . DOI: 10.1017/ So950268807008151 PMID: 17335631

8. Department of Health. National immunisation programme planned changes for 2013 to 2014. London: Department of Health. [Accessed 27 Oct 2014]. Available from: https://www. gov.uk/government/publications/national-immunisationprogramme-planned-changes-for-2013-to-2014

9. News BBC. Babies to get 'gut bug vaccine'. BBC [Internet]. 10 Nov 2012. Available from: http://www.bbc.co.uk/news/ health-20268350

10. Ruuska T, Vesikari T. Rotavirus disease in Finnish children: use of numerical scores for clinical severity of diarrhoeal episodes.Scand J Infect Dis. 1990;22(3):259-67. .DOI: 10.3109/00365549009027046 PMID: 2371542

11. Department of Health. NHS reference costs 2012 to 2013. London: Department of Health. [Accessed 29 Oct 2014]. Available from: https://www.gov.uk/government/publications/ nhs-reference-costs-2012-to-2013

12. R Core Team. R: A Language and Environment for Statistical Computing [Internet]. Vienna, Austria: R Foundation for Statistical Computing; 2014. Available from: http://www.Rproject.org/

13. Office for National Statistics. Population Estimates for England and Wales Mid-2012. London: Office for National Statistics. [Accessed 27 Oct 2014]. Available from: http://www.ons.gov. uk/ons/rel/pop-estimate/population-estimates-for-englandand-wales/mid-2012/index.html

14. Feikin DR, Scott JAG, Gessner BD. Use of vaccines as probes to define disease burden.Lancet. 2014:383(9930):1762-70. .DOI: 10.1016/S0140-6736(13)61682-7 PMID: 24553294

15. Rodrigues F, Iturriza-Gómara M, Marlow R, Gray J, Nawaz $\mathrm{S}$, Januário $\mathrm{L}$, et al. The evolving epidemiology of rotavirus gastroenteritis in central Portugal with modest vaccine coverage. J Clin Virol. 2013;56(2):129-34. .DOI: 10.1016/j. jcv.2012.10.016 PMID: 23238239

16. Sáfadi MAP, Berezin EN, Munford V, Almeida FJ, de Moraes JC, Pinheiro CF, et al. Hospital-based surveillance to evaluate the impact of rotavirus vaccination in São Paulo, Brazil. Pediatr Infect Dis J. 2010;29(11):1019-22.PMID: 20543761

17. Räsänen S, Lappalainen S, Salminen M, Huhti L, Vesikari T. Noroviruses in children seen in a hospital for acute gastroenteritis in Finland.Eur J Pediatr. 2011;170(11):1413-8. DOI: 10.1007/s00431-011-1443-4 PMID: 21465124

18. Hahné S, Hooiveld M, Vennema H, van Ginkel A, de Melker H, Wallinga J, et al. Exceptionally low rotavirus incidence in the Netherlands in 2013/14 in the absence of rotavirus vaccination. Euro Surveill. 2014;19(43):20945 . DOI: 10.2807/1560-7917. ES2014.19.43.20945 PMID: 25375899

19. RotaBel Study Group,Braeckman T, Van Herck K, Meyer N, Pirçon J-Y, Soriano-Gabarró M, Heylen E, et al. . Effectiveness of rotavirus vaccination in prevention of hospital admissions for rotavirus gastroenteritis among young children in Belgium: case-control study.BM). 2012;345(aug08 1):e4752. .DOI: 10.1136/bmj.e4752 PMID: 22875947

20. Marlow R, Ferreira M, Cordeiro E, Trotter C, Januário L, Finn A, et al. Case control study of rotavirus vaccine effectiveness in Portugal during 6 years of private market use. Pediatr Infect Dis J. 2015 May;34(5):509-12;34(5):509-12.

21. Buttery JP, Lambert SB, Grimwood K, Nissen MD, Field EJ, Macartney KK, et al. Reduction in rotavirus-associated acute gastroenteritis following introduction of rotavirus vaccine into Australia's National Childhood vaccine schedule. Pediatr Infect Dis J. 2011;30(1) Suppl;S25-9. .DOI: 10.1097| INF.obo13e3181fefdee PMID: 21183837

22. Atkins KE, Shim E, Pitzer VE, Galvani AP. Impact of rotavirus vaccination on epidemiological dynamics in England and Wales.Vaccine. 2012;30(3):552-64. .DOI: 10.1016/j. vaccine.2011.11.064 PMID: 22133508

23. Atchison C, Lopman B, Edmunds WJ. Modelling the seasonality of rotavirus disease and the impact of vaccination in England and Wales.Vaccine. 2010;28(18):3118-26. .DOI: 10.1016/j. vaccine.2010.02.060 PMID: 20197142

24. Rijksinstituut voor Volksgezondheid en Milieu (RIVM). Infectieziekten Bulletin. 2015;26(2):54. Bilthoven: RIVM. Dutch. Available from: http://www.rivm.nl/dsresource?objectid=rivmp :272637\&type=org\&disposition=inline

25. Tate JE, Cortese MM, Payne DC, Curns AT, Yen C, Esposito $\mathrm{DH}$, et al. Uptake, impact, and effectiveness of rotavirus vaccination in the United States: review of the first 3 years of postlicensure data. Pediatr Infect Dis J. 2011;30(1) Suppl;S56-60. .DOI: 10.1097/INF.obo13e3181fefdco PMID: 21183842

26. Tate JE, Haynes A, Payne DC, Cortese MM, Lopman BA, Patel $M M$, et al. Trends in national rotavirus activity before and after introduction of rotavirus vaccine into the national immunization program in the United States, 2000 to 2012. Pediatr Infect Dis J. 2013;32(7):741-4. .DOI: 10.1097/ INF.obo13e31828d639C PMID: 23426425

27. Centers for Disease Control and Prevention (CDC),Elam-Evans LD, Yankey D, Singleton JA, Kolasa M. National, state, and selected local area vaccination coverage among children aged 19-35 months - United States, 2013.MMWR Morb Mortal Wkly Rep. 2014;63(34):741-8.PMID: 25166924

28. Zeller M, Rahman M, Heylen E, De Coster S, De Vos S, Arijs I, et al. Rotavirus incidence and genotype distribution before and after national rotavirus vaccine introduction in Belgium. Vaccine. 2010;28(47):7507-13. .DOI: 10.1016/j. vaccine.2010.09.004 PMID: 20851085

29. Public Health England (PHE). National rotavirus immunisation programme: preliminary data for England, October 2013 to September 2014. Health Protection Report. 2014 Oct 24;8(41). Available from: https://www.gov.uk/government/ uploads/system/uploads/attachment_data/file/367155/ hpr4114_rotavirus_v4.pdf

30. Snelling TL, Andrews RM, Kirkwood CD, Culvenor S, Carapetis JR. Case-control evaluation of the effectiveness of the $\mathrm{G}_{1} \mathrm{P}[8]$ human rotavirus vaccine during an outbreak of rotavirus $\mathrm{G}_{2} \mathrm{P}[4]$ infection in central Australia.Clin Infect Dis. 2011;52(2):191-9. .DOI: 10.1093/cid/ciq101 PMID: 21288843

31. Justino MCA, Linhares AC, Lanzieri TM, Miranda Y, Mascarenhas JDP, Abreu E, et al. Effectiveness of the monovalent $\mathrm{G}_{1} \mathrm{P}[8]$ human rotavirus vaccine against hospitalization for severe $\mathrm{G}_{2} \mathrm{P}[4]$ rotavirus gastroenteritis in Belém, Brazil. Pediatr Infect Dis J. 2011;30(5):396-401. .DOI: 10.1097/INF.ob013e3182055Cc2 PMID: 21150692

32. Gurgel RQ, Alvarez AJ, Rodrigues A, Ribeiro RR, Dolabella SS, Da Mota NL, et al. Incidence of rotavirus and circulating genotypes in Northeast Brazil during 7 years of national rotavirus vaccination. PLoS ONE. 2014;9(10):e110217. .DOI: 10.1371/journal.pone.0110217 PMID: 25360784

33. Harris JP, Jit M, Cooper D, Edmunds WJ. Evaluating rotavirus vaccination in England and Wales. Part I. Estimating the burden of disease.Vaccine. 2007;25(20):3962-70. .DOI: 10.1016/j. vaccine.2007.02.072 PMID: 17395343 